\title{
The viability of microwave sintering process to produce a ceramic tool insert
}

\author{
S.H. Thauri, B.T.H.T Baharudin ${ }^{2}$, Z. Leman ${ }^{2 *}$ and S.M Tahir \\ ${ }^{1}$ Faculty of Mechanical Engineering, Universiti Putra Malaysia, \\ 43400, Serdang, Malaysia, \\ *Email: shahdura_ht@hotmail.com \\ Phone: +609193217001; Fax: +6094246222
}

\begin{abstract}
Microwave processing of ceramics is fast emerging as a new field of ceramic processing and material synthesis. The past year has witnessed significant progress in the aspects of commercialization and application of the technology in new areas. Due to that reason, several experiments were conducted on microwave heating of ceramics. The aim of the study is to investigate i) whether microwave is a viable alternative to produce sintering parts, ii) the effect of soaking time on the properties of the sample, and iii) the influence of several binders including nickel, ferum, chromium and cobalt to tungsten carbide cermets. The study involved studying the density, hardness and microstructure of the sintered samples. The samples were compacted using an Instron machine at $200 \mathrm{MPa}$ in a cylindrical shape using pallet press with a height of $10 \mathrm{~mm}$ and a diameter of $20 \mathrm{~mm}$ and sintered in microwave hybrid sintering at $1450^{\circ} \mathrm{C}$ for two different soaking time (10 min and $20 \mathrm{~min}$ ). The soaking time of $10 \mathrm{~min}$ showed better density, hardness and microstructural results compared to those of $20 \mathrm{~min}$. In comparing between the binders, $\mathrm{Ni}$ and $\mathrm{Fe}(\mathrm{Ni}-\mathrm{Fe})$ showed better results compared to $\mathrm{Ni}$ and $\mathrm{Cr}$. While cobalt, nickel and ferum (Co-Ni-Fe) had enhanced results compared to $\mathrm{Co}$ and $\mathrm{Cr}(\mathrm{Co}-\mathrm{Cr})$. Although there are a lot of research studies on several other binders, there is still no finding on the use of microwave hybrid sintering to sinter different mixing binders of tungsten carbide cermets. Therefore, in this research, it is believed that the use of microwave hybrid sintering is viable to sinter tungsten carbide cermets with different binders. The density result showed that each composition of the sintered density was higher compared to green density, which increased by $30 \%$ than the green density on average. On the other hand, the hardness results from the commercial cutting tool for tungsten carbide cermet was in the range of 80 to $92 \mathrm{HRA}$ and the highest result for hardness in this research was $84.3 \mathrm{HRA}$, which means that the insert can be used for commercial use depending on the application.
\end{abstract}

Keywords: Microwave; tungsten carbide; alternative binder; compaction; density.

\section{INTRODUCTION}

Powder metallurgy (PM) is a process whereby a material powder is compacted as a green body and sintered to a net shape at elevated temperatures. There are challenging demands from the PM industry for new and improved sintering process with finer microstructures and enhanced physical and mechanical properties [1,2]. PM components can be made by pressing and sintering powders. The major processing steps are compaction and sintering. PM is involved in many processes such as studies on properties and microstructure of samples, as well as grain growth control in sintering process [3]. Many researchers have 
used conventional sintering [3-6]. Newer processes exist such as plastic sintering, liquid phase sintering, spark plasma sintering and pressureless sintering [7-10]. However, microwave heating is different from all of the conventional ones in the way heat is transferred, which is by radiation and convection heating. In contrast, microwave energy is delivered directly to the material through molecular interaction with electromagnetic field. Microwave heating is the transfer of electromagnetic energy to thermal energy, which is an energy conversion instead of heat transfer [3]. The traditional process of sintering involves heating at a slow rate, that is less than $10^{\circ} \mathrm{C}$ per minute. Not only this increases the process time, but it also results in significant microstructure coarsening (grain growth) during sintering, leading to the degradation of mechanical properties. Hence, it is envisaged that a fast heating rate would mitigate this problem [4]. New developments and innovative ideas in the area of materials processing have often led to the discovery of new materials processing with interesting and useful properties and new technologies which are faster, better, cheaper and greener. Striking examples of such innovations are recent developments in the area of microwave processing of ceramics. Although many potential advantages of utilizing microwaves to process ceramics have long been recognized, it is only now that this field has finally been shown to take-off stage [5]. Microwave heating was conceived over 50 years ago, but its use in ceramic processing is relatively new. The starting material for most ceramics and similar materials is a type of powder that must be glued together to create a solid. Certain powders can be joined into useful solid by simply blending the powder particles together by high temperature self-diffusions, which is called sintering. This operation removes the spaces between the powder particles. In order to meet the requirements of specific applications, WC hardmetals may contain small amounts of binding elements such as cobalt, nickel or iron. The use of $\mathrm{Ni}$ instead of $\mathrm{Co}$ as a binder material could lead to higher corrosion resistance [11]. However, the mechanical properties of WC composite containing nickel may deteriorate since hardmetals based on WC-Co usually have better combinations of mechanical properties compared to WC-Ni grades [4]. According to Almond and Roebuck (1988), the compressive properties of WC-Co hardmetals are usually superior to those of WC-(Co-Ni) hardmetals. In most cases, cobalt has been used in the tough metal binder phase, due to its excellent wetting, adhesion and adequate mechanical properties [12].

Exceptional wear resistance of cemented carbides, owing to the combination of a tough metal binder with a hard carbide, has resulted in their applications in many engineering fields. In addition to their good performance in mining and cutting tool applications, cemented carbides are increasingly used in a variety of other industrial applications, such as seal rings, linings, valves, jet nozzles, saw blades, fluid mixers and conveyor belt scrapers. These applications differ from the traditional uses, in that significantly longer lifetime is demanded and components are expected to remain in service for several years. If components are subjected to wear as well as being in contact with chemically aggressive environments, corrosion can play a major role in the degradation of the surface and can significantly accelerate wear [11-13]. Interest and research activity in microwave processing are continuously increasing, and the use of the microwave technology in industrial application is also growing with new developments in both engineering and design of microwave systems. This study is undertaken with the aim to understand the effect of microwave synthesis and sintering process on the physical behaviour of powder ceramic part with respect to hardness and density. 


\section{EXPERIMENTAL SETUP}

\section{Experimental Procedure}

In order to achieve the aim of the research, the weight percentage of each material was selected. A round shape insert was developed in-house using tungsten carbide with cobalt and binder powder. The normal production using furnace to melt and bind the powder into solid was replaced with the sintering process using microwave energy. The initial stage of the research focused on developing the compacted powder inserts of circular shape to take advantage of multiple cutting edges. The second stage of the research carried out preliminary study on the sintering parameters. Once the level of microwave intensity, compaction force and other parameters were determined for minimal formation of sintered inserts, the full production process was carried out. In this process, two levels of microwave sintering holding time and four different powder compositions were chosen. In the final stage of the research, a confirmation test to evaluate the result was done. The mechanical properties of the produced inserts were tested such as the hardness and density of the insert to see which powder composition would give better results, such that it is denser and less porous.

The base powder for this experiment was tungsten carbide (WC) powder, followed by the binder powder. The binder powder consisted of nickel $(\mathrm{Ni})$, ferum $(\mathrm{Fe})$, cobalt $(\mathrm{Co})$ and chromium $(\mathrm{Cr})$. Tungsten carbide is a well-known material used for cutting tools and other wear products and machine components with high melting point of $2870{ }^{\circ} \mathrm{C}$. Tungsten carbide is denser than steel or titanium. Due to high temperature, the conventional sintering method requires a lot of energy and long processing time. The compositions are listed in Table 1 in term of weight percentage of each sample. There were 24 samples and the samples were divided into two groups, group A and group B, which consisted of soaking time. As for the powder composition, there are different opinions about the limits of tungsten carbide. These limits vary between $30 \%$ and $90 \%$, and WC $90 \mathrm{wt} \%$ and $98 \mathrm{wt} \%$ in Brożek, Młynarczykowska [14]. Moreover, in his research on alternative binders, Waldorf, Liu [15] also varied the composition, where WC was varied in the range of 90 to $98 \%$, and the rest were mixed with different binders. The samples were then tested in a turning machine to see the wear of the sample. Furthermore, MUREŞAN [16] also used the same range of composition as stated in Table 1 to mix WC with $\mathrm{Ni}, \mathrm{Fe}, \mathrm{Co}$ and $\mathrm{Cr}$, except that he varied the composition of Wc-Ni-Fe. Also, a sample had added $\mathrm{Cr}$, for which the objective was to see the effect of $\mathrm{Cr}$ on the density, elongation and yield limit of Wc-Ni-Fe. The samples were compacted at 200 $\mathrm{MPa}$ and sintered in hydrogen environment using liquid phase sintering in a furnace at $1500^{\circ} \mathrm{C}$. While, Zhou, Wang [17] reported that his research objective was to see the addition of $\mathrm{Fe}$ and $\mathrm{Cr}$, the $\mathrm{Ni}$ addition between 0.1 to $1 \%$ could greatly improve the relative density and maintain high thermal conductivity of $\mathrm{W}$ at the same time. He also compared between 5, 10 and 15 minutes soaking time. The samples were compacted at $600 \mathrm{MPa}$ and heated in microwave sintering at $1450^{\circ} \mathrm{C}$. Therefore, the purpose of this experiment on binder mixing was first to compare the effect of the addition of $\mathrm{Ni}$ and $\mathrm{Fe}$ with $\mathrm{Ni}$ and $\mathrm{Cr}$ with to the highest percentage of WC in terms of density, hardness and microstructure. Second was to compare the effect of the addition of $\mathrm{Co}$ and $\mathrm{Cr}$ with $\mathrm{Fe}$, $\mathrm{Ni}$ and Co to the highest percentage of WC. This is to see which binder can produce better result, whether the addition of the binders has better effect than the highest percentage of $\mathrm{WC}$, and to compare the results with other findings.

The base powder (WC) in the size of 1-5 microns and all of the binders ( $\mathrm{Ni}, \mathrm{Fe}$, $\mathrm{Co}$ and $\mathrm{Cr}$ ) were first weighed based on weight percentage. The size of ferum was 1-9 
microns, nickel 4-8 microns, cobalt 1 microns and chromium was 1-5 microns. All of the powder sizes were chosen based on previous research $[15,16]$. In order to achieve the height of $10 \mathrm{~mm}$, each sample must weigh $25.5 \mathrm{~g}$. The percentage of each powdered sample was based on Breval, Cheng [18].

Table 1. Powder composition.

\begin{tabular}{|c|c|c|}
\hline \multicolumn{3}{|c|}{ Tungsten Carbide with Nickel and Ferum } \\
\hline $\mathrm{A} 1,90 \mathrm{Wc} 7 \mathrm{Ni} 3 \mathrm{Fe}$ & $\mathrm{A} 2,92 \mathrm{Wc} 1 \mathrm{Ni} 7 \mathrm{Fe}$ & $\mathrm{A} 3,97 \mathrm{Wc} 1 \mathrm{Ni} 2 \mathrm{Fe}$ \\
\hline $\mathrm{B} 1,90 \mathrm{Wc} 7 \mathrm{Ni} 3 \mathrm{Fe}$ & $\mathrm{B} 2,92 \mathrm{Wc} 1 \mathrm{Ni} 7 \mathrm{Fe}$ & $\mathrm{B} 3,97 \mathrm{Wc} 1 \mathrm{Ni} 2 \mathrm{Fe}$ \\
\hline \multicolumn{3}{|c|}{ Tungsten Carbide with Nickel and Chromium } \\
\hline $\mathrm{A} 4,90 \mathrm{Wc} 3 \mathrm{Ni} 7 \mathrm{Cr}$ & $\mathrm{A} 5,92 \mathrm{Wc} 7 \mathrm{Ni} 1 \mathrm{Cr}$ & $\mathrm{A} 6,97 \mathrm{Wc} 2 \mathrm{Ni} 1 \mathrm{Cr}$ \\
\hline $\mathrm{B} 4,90 \mathrm{Wc} 3 \mathrm{Ni} \mathrm{Cr}$ & $\mathrm{B} 5,92 \mathrm{Wc} 7 \mathrm{Ni} 1 \mathrm{Cr}$ & $\mathrm{B} 6,97 \mathrm{Wc} 2 \mathrm{Ni} 1 \mathrm{Cr}$ \\
\hline \multicolumn{3}{|c|}{ Tungsten Carbide with Cobalt and Chromium } \\
\hline $\mathrm{A} 7,90 \mathrm{Wc} 7 \mathrm{Co} 3 \mathrm{Cr}$ & $\mathrm{A} 8,92 \mathrm{Wc} 1 \mathrm{Co} 7 \mathrm{Cr}$ & A9, 97Wc2Co1Cr \\
\hline $\mathrm{B} 7,90 \mathrm{Wc} 7 \mathrm{Co} 3 \mathrm{Cr}$ & $\mathrm{B} 8,92 \mathrm{Wc} 1 \mathrm{Co} 7 \mathrm{Cr}$ & B9, 97Wc2Co1Cr \\
\hline \multicolumn{3}{|c|}{ Tungsten Carbide with Ferum, Nickel and Cobalt } \\
\hline A10, & A11, & A12, \\
\hline $90 \mathrm{Wc} 3 \mathrm{Fe} 3.5 \mathrm{Ni} 3.5 \mathrm{Co}$ & 92Wc7Fe1.5Ni1.5Co & 97Wc1Fe1Ni1Co \\
\hline B10, & & B12, \\
\hline $90 \mathrm{Wc} 3 \mathrm{Fe} 3.5 \mathrm{Ni} 3.5 \mathrm{Co}$ & $\mathrm{B} 11,92 \mathrm{Wc} 7 \mathrm{Fe} 1.5 \mathrm{Ni} 1.5 \mathrm{Co}$ & 97Wc1Fe1Ni1Co \\
\hline
\end{tabular}

Before mixing and compacting, the powders were weighed using Sartorius GD503. It is a weighing machine with an accuracy of up to $0.001 \mathrm{~g}$. Each test specimen was compacted using $25.5 \mathrm{~g}$ of powder in order to achieve a height of $10 \mathrm{~mm}$. All of the powders were sourced by Accumet Materials Co., and the material safety data sheets are attached in Appendix A. All measurements were taken three times to obtain the average value. The powders were mixed in a powder rotator for three hours at a speed of $85 \mathrm{rpm}$. Once the powders were properly mixed, it was then ready for compaction. In this procedure, an Instron machine model 3382 was used to compact at a pressure of $200 \mathrm{MPa}$ . The samples were then sintered in a microwave with two different soaking time.

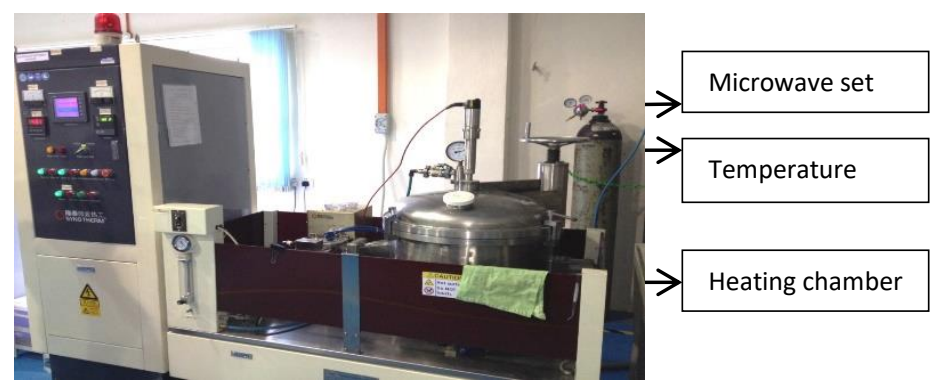

(a)

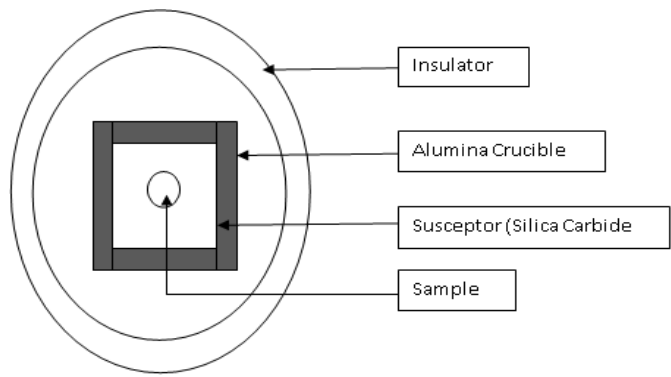

(b)

Figure 1. (a) Experimental setup; (b) Sample setup in the microwave. 


\section{RESULTS AND DISCUSSION}

\section{Density}

Table 2 shows that the density of the samples increased after the sintering process. It also shows the difference in density between the green and sintered samples. Each composition shows that the density of the sintered sample was higher than the green sample, with an average increase by $30 \%$ than the green sample. This is due to the grain boundary between the particles, whereby during heating, the grain boundary between particles came close to each other making them denser after sintering [15]. For the comparison between the soaking time for all samples, it can be seen clearly that 10 minutes soaking time gave better result compared to that of 20 minutes. Ten minutes soaking time gave higher density compared to that of 20 minutes due to the grain growth of each particle, whereby prolonged heating of a sample increased the kinetics of the grain growth in the sample [19]. Based on this, all samples were differentiating based on the 10 minutes soaking time. It was stated in Bao, Yi [20] that 5,10,15,and 60 minutes soaking time do not have any effect on grain size effect WC-Co however 5 minutes soaking time gave a full densification. Therefore, it can be said that the binders of $\mathrm{WC}$, which is $\mathrm{Ni}$, $\mathrm{Fe}, \mathrm{Co}$ and $\mathrm{Cr}$ had certain effect on WC such that the density of the samples of 10 minutes soaking time were better than that of 20 minutes.

Comparing the density of WCNiFe and $\mathrm{WCNiCr}$ (Figures 2 and 3), it was shown that the sample with higher composition of tungsten (97WC1Ni2Fe) was denser, followed by the sample with higher composition of $\mathrm{Ni}(90 \mathrm{WC} 7 \mathrm{Ni} 3 \mathrm{Fe}$ ) and $\mathrm{Fe}$ (92WC1Ni7Fe) and lastly, $\mathrm{Cr}(90 \mathrm{WC} 7 \mathrm{Ni} 3 \mathrm{Cr})$. Tungsten is known to have high melting point, high hardness, high thermal and electrical conductivities and relatively high chemical stability [21]. Nickel has the highest density compared to chromium, due to the fact that the addition of $\mathrm{Ni}$ is known as a binder that improves densification of tungsten. While for the properties of chromium, which have been studied by a lot of researchers, it was found that the addition of chromium as a binder in any mixture will not increase the strength, but only improve the cutting tool performance [22]. Besides, Zhou found that the relative density of $\mathrm{W}$ can be improved by the addition of $\mathrm{Fe}, \mathrm{Cr}$, and $\mathrm{Ni}$ at a content of 1 wt.\%. The addition of $\mathrm{Fe}$ and $\mathrm{Ni}$ was more effective and could increase the relative density of $\mathrm{W}$ from $92.5 \%$ up to $98.6 \%$ and $99.2 \%$, respectively compared to adding Cr. It was also stated that $1 \%$ of $\mathrm{Ni}$ addition resulted in about $99 \%$ densification for 5,15 and 30 minutes holding time.

On the other hand, the density results varied for the samples of WC-Co-Ni-Fe and WC-Co-Cr (Figures 4 and 5). The density of the compositions with higher tungsten, (97WC2Ni1Cr) and 97WC1Co1Ni1Fe, was higher, followed by the composition with higher cobalt, nickel and ferum, $(92 \mathrm{WC} 7 \mathrm{Co} 0.5 \mathrm{Ni} 0.5 \mathrm{Fe})$ and lastly chromium, (92WC1Co7Cr). Although for both, samples with higher cobalt had higher density however samples that being mixed together with $\mathrm{Co}, \mathrm{Ni}$ and $\mathrm{Fe},(92 \mathrm{WC} 7 \mathrm{Co} 0.5 \mathrm{Ni} 0.5 \mathrm{Fe})$ has a higher density compare to $\mathrm{Co}$ and $\mathrm{Cr}$, (90WC7Co3Cr). Various Kennametal patents described the use of $\mathrm{Fe}, \mathrm{Ni}$, and $\mathrm{Co}$ as binder constituents, as they improve toughness compared to Co alone [21]. Gonzalez was able to produce $\mathrm{Fe}-\mathrm{Ni}$ bonded WC samples with similar hardness to that of WC-Co materials, and was also able to achieve relatively increased toughness by way of heat treatment of the WC-Fe-Ni samples [23]. As in several other studies, it has been stressed that a proper amount of carbon must be added to the binder for sintering and heat treatment in order to produce the most advantageous phase structure of the bonded system example free of brittle phase carbides from insufficient carbon and free of soft graphite resulting from excess carbon [19]. Thus, this 
shows that although Ni-Fe binders were added to WC samples, the result for higher cobalt composition was better than higher Ni-Fe composition. This observation is also supported by Holleck [22], which why $\mathrm{Cr}$ could not produce better result than other binders. Although it was said that small amounts of Cr to Co binder in WC-Co is an improvement mechanism for cutting tool performance, this could not be shown to improve the density of the sample by adding chromium. Moreover, MUREŞAN [16] stated that the element of $\mathrm{Cr}$ forms interfaces with the elements of $\mathrm{W}, \mathrm{Ni}$, and $\mathrm{Fe}$ and segregations along the alloy interface, which cause interface corrosion and determines low mechanical properties of the samples. The result for the density of each sample is summarized in Table 2 and the comparison can clearly been seen in Figures 2 to 5.

Table 2. Density result of Wc-Ni-Fe, Wc-Ni-Cr, Wc-Co-Ni-Fe and Wc-Co-Cr for 10 min and 20 min soaking time.

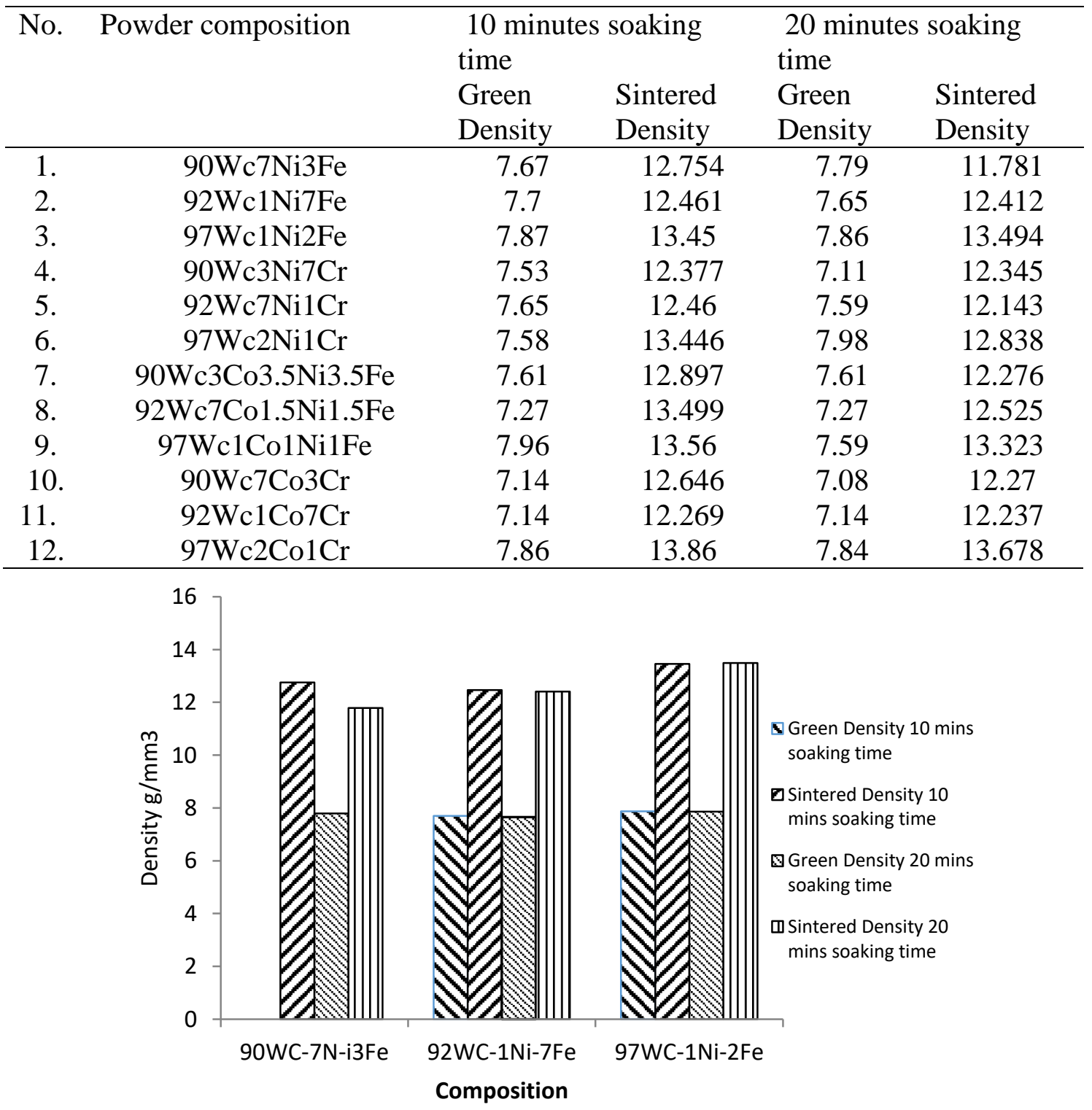

Figure 2. Density for 10 min soaking time and density for 20 min soaking time for Wc$\mathrm{Ni}-\mathrm{Fe}$. 


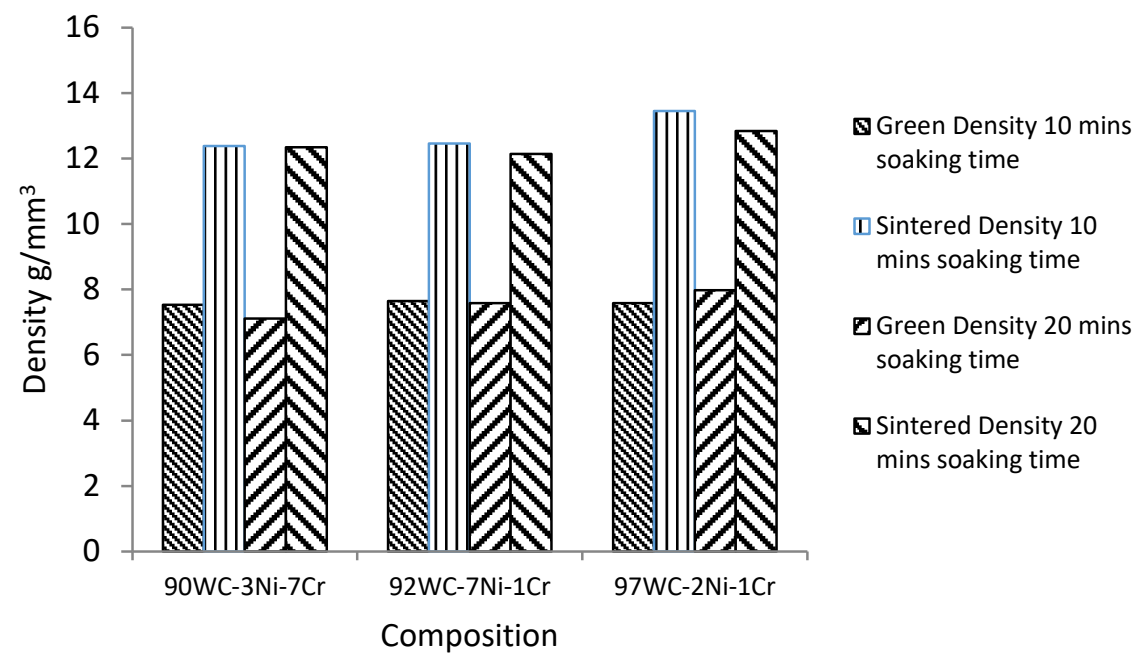

Figure 3.Density for $10 \mathrm{~min}$ soaking time and density for $20 \mathrm{~min}$ soaking time for Wc$\mathrm{Ni}-\mathrm{Cr}$.

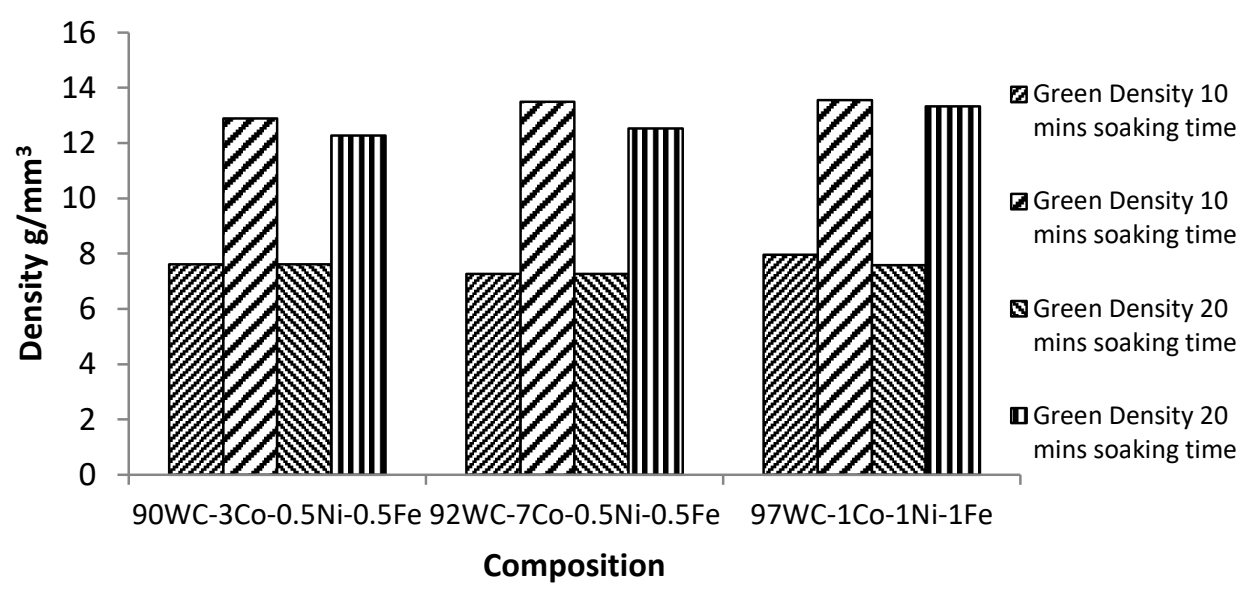

Figure 4. Density for $10 \mathrm{~min}$ soaking time and density for 20 min soaking time for WCCo-Ni-Fe.

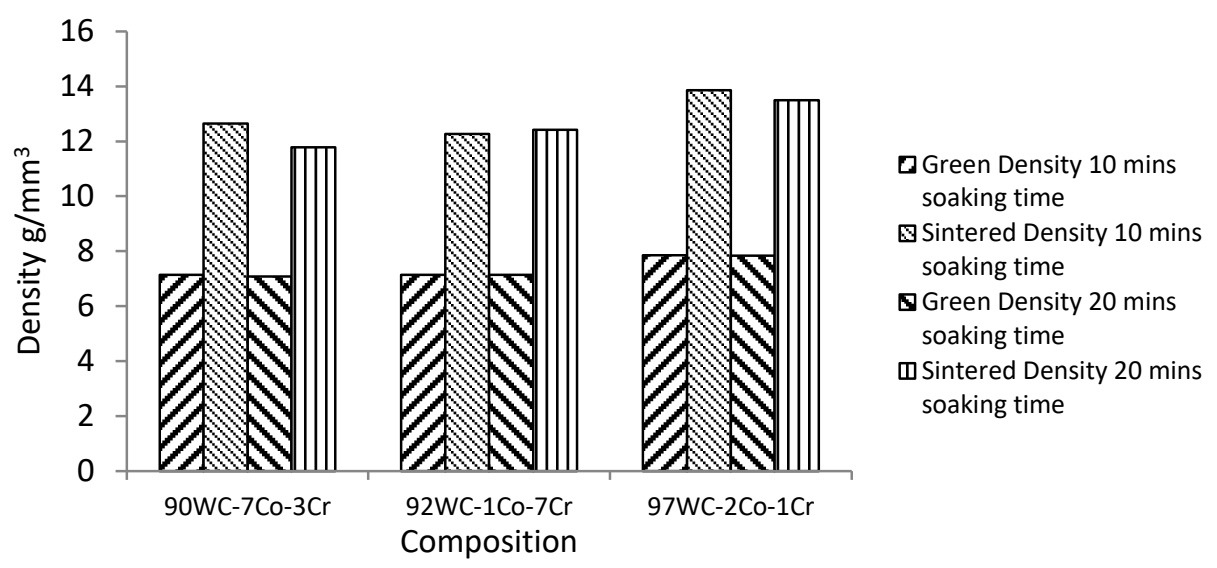

Figure 5. Density for $10 \mathrm{~min}$ soaking time and density for 20 min soaking time for WCCo-Cr. 


\section{Hardness}

All of the samples had similar hardness result as that of density in terms of soaking time, which shows that samples of 10 minutes soaking time had better density and hardness results. Based on Zhou, Wang [17], who also compared 5, 15 and 30 minutes soaking time, and found that 5 minutes soaking time had better result than others. Longer holding time can enhance atomic diffusion during the sintering process, which leads to coarse grain. Based on Table 3, we can clearly see the difference between each sample. In comparison hardness result from the commercial cutting tool on Tungsten Carbide, the range is 80 to 92 HRA and the highest result for hardness in this research was 84.3 HRA, which means that the insert can be used for commercial usage depending on the application [17].

Table 3. Hardness result for Wc-Ni-Fe, Wc-Ni-Cr, Wc-Co-Ni-Fe and $\mathrm{Wc}-\mathrm{Co}-\mathrm{Cr}$ for $10 \mathrm{~min}$ and 20 min soaking time.

\begin{tabular}{cccc}
\hline No. & Powder composition & $\begin{array}{c}\text { 10 minutes soaking time } \\
\text { Hardness, HRA }\end{array}$ & $\begin{array}{c}\text { 20 minutes soaking time } \\
\text { Hardness, HRA }\end{array}$ \\
\hline 1. & $90 \mathrm{Wc7Ni3Fe}$ & 68.7 & 61.6 \\
2. & $92 \mathrm{Wc1Ni7Fe}$ & 78.7 & 78.5 \\
3. & $97 \mathrm{Wc1Ni2Fe}$ & 74.5 & 69.4 \\
4. & $90 \mathrm{Wc} 3 \mathrm{Ni7Cr}$ & 70.9 & 67.3 \\
5. & $92 \mathrm{Wc7Ni1Cr}$ & 79.3 & 62.4 \\
6. & $97 \mathrm{Wc} 2 \mathrm{Ni1Cr}$ & 62.0 & 55.9 \\
7. & $90 \mathrm{Wc} 3 \mathrm{Co} 3.5 \mathrm{Ni3} .5 \mathrm{Fe}$ & 76.7 & 63.5 \\
8. & $92 \mathrm{Wc7Co1.5Ni1.5Fe}$ & 84.3 & 82.1 \\
9. & $97 \mathrm{Wc1Co} 1 \mathrm{Ni} 1 \mathrm{Fe}$ & 73.2 & 78.2 \\
10. & $90 \mathrm{Wc7Co3Cr}$ & 83.6 & 74.8 \\
11. & $92 \mathrm{Wc1Co7Cr}$ & 44.5 & 48.7 \\
12. & $97 \mathrm{Wc} 2 \mathrm{Co} 1 \mathrm{Cr}$ & 70.8 & 69.8 \\
\hline
\end{tabular}

\section{Hardness of Wc-Ni-Fe and Wc-Ni-Cr specimens}

For both samples, Figures 6 and 7 show that the composition with the highest $\mathrm{Ni}$ (Figure 7) had greater hardness followed by samples with higher Fe, WC and lastly Cr. On the other hand, if a comparison is made between both samples, on average, samples with $\mathrm{Fe}$ and $\mathrm{Ni}$ that bonded with WC had better result compared to samples that bonded with $\mathrm{Ni}$ and $\mathrm{Cr}$. This can be seen in the average of the results, where for $\mathrm{Ni}, \mathrm{Fe}$ is 73.9 while $\mathrm{Ni}, \mathrm{Cr}$ is 65.1 , which means that the difference in terms of percentage was $0.11 \%$. It has been stated in the density result that the addition of $\mathrm{Ni}$ improved the densification of tungsten, while $\mathrm{Cr}$ produced the opposite result [22]. Comparing between A1 and A5, both samples had higher percentage of $\mathrm{Ni}$. Therefore, it can be said that when $\mathrm{Ni}$ is high in percentage, $\mathrm{Fe}$ is not a good combination with $\mathrm{Ni}$ as compared to $\mathrm{Cr}$. Where $\mathrm{A} 1$ is 68.7 , while A5 is 79.3 of hardness result. Moreover, from the results shown in both figures, it can be noted that the addition of greater amount of WC affected the hardness of a sample, which means that higher percentage of WC produces harder sample. Furthermore it can be clearly seen in Figure 6 and Figure 7 that the higher is the density, the harder is the sample. 


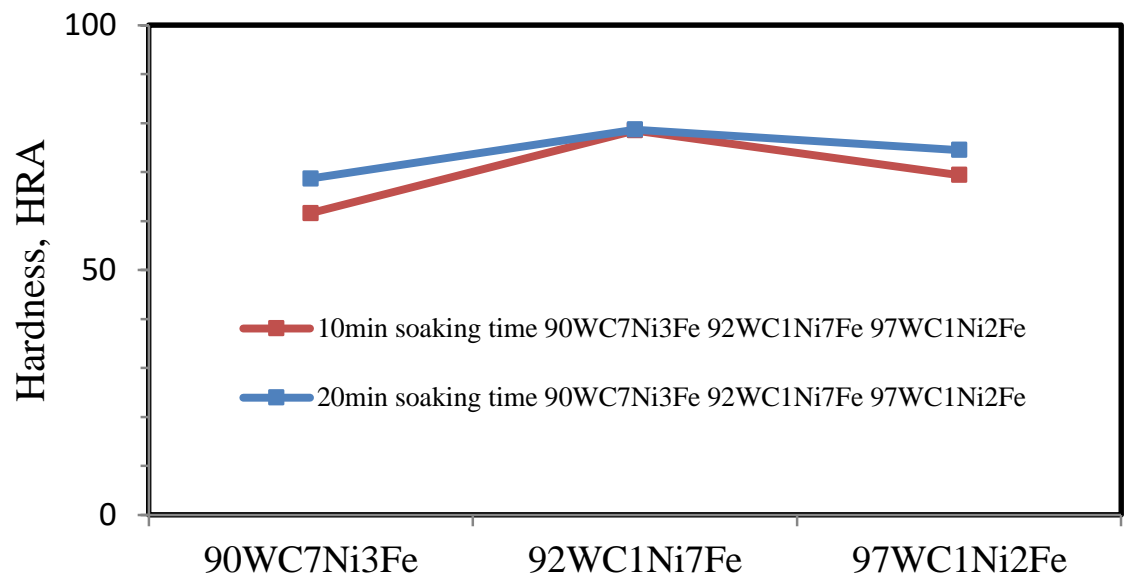

Figure 6. Hardness for $10 \mathrm{~min}$ and 20 min soaking time for WC-Ni-Fe.

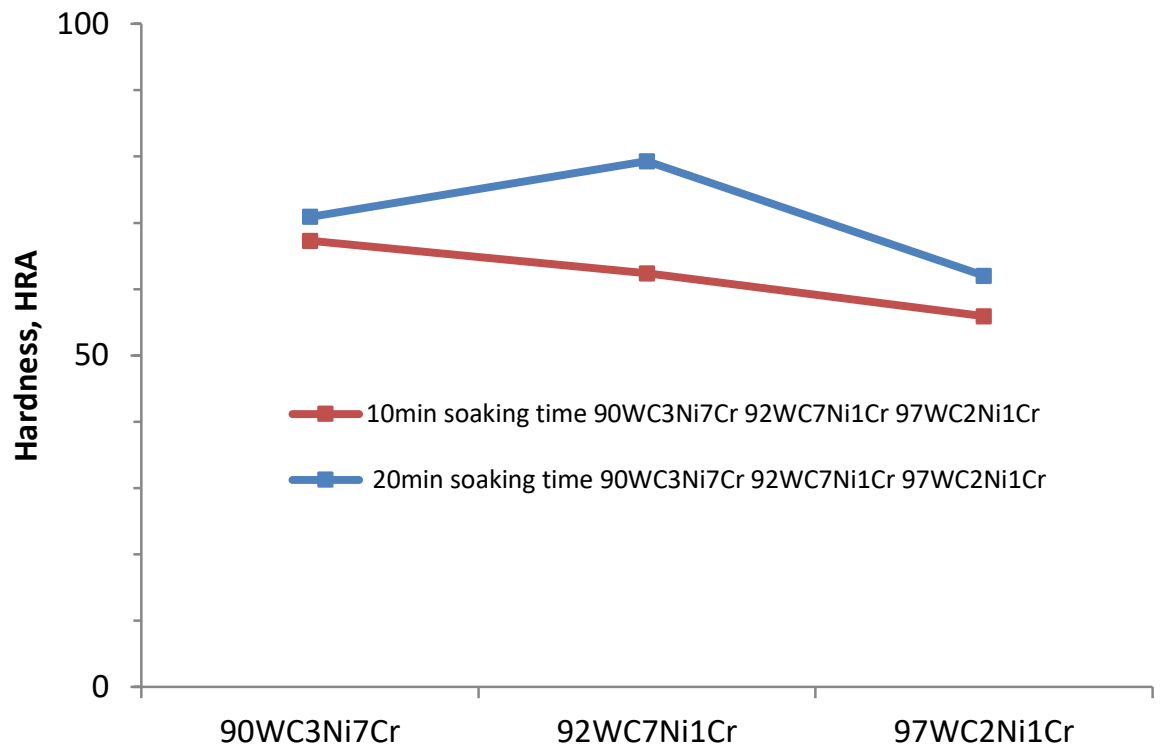

Figure 7. Hardness for $10 \mathrm{~min}$ and 20 min soaking time for $\mathrm{WC}-\mathrm{Ni}-\mathrm{Cr}$

\section{Hardness of Wc-Co-Ni-Fe and Wc-Co-Cr specimens}

Comparing between both binders in Figures 8 and 9, it can be seen that samples with higher cobalt had greater hardness, which are A8, 84.3 and A10 83.6 when add to tungsten as compared to others that have been tried before [24]. This is followed by samples with higher binder of $\mathrm{Ni}$ and Fe, WC and lastly Cr. Willert-Porada [21] and Holleck [22] have explained on why binder with higher composition of Co has more superior result compared to others. Other researchers have tried to replace Co with $\mathrm{Ni}$ and Fe and found that it produced similar hardness to that of WC-Co. Although both binders with higher percentage of cobalt had greater hardness compared to other samples. However, samples that bind with $\mathrm{Co}, \mathrm{Ni}$ and $\mathrm{Fe}, \mathrm{A} 8$ has higher hardness result in average of 78.1 as compared to the sample that bind with $\mathrm{Co}$ and $\mathrm{Cr}$, A10 which is 66.3. On the other hand, the difference in percentage is $0.15 \%$. It can be seen that the combination of WC with $\mathrm{Co}, \mathrm{Ni}$ and $\mathrm{Fe}$ produced better hardness and density results compared to WC with $\mathrm{Co}$ and $\mathrm{Cr}$. 


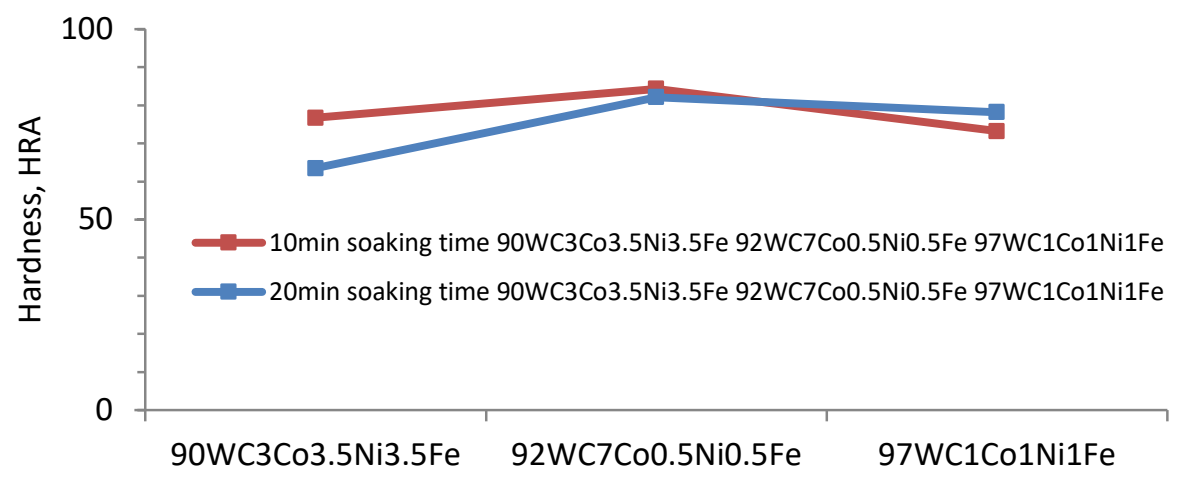

Figure 8. Hardness for 10min and 20 min soaking time for WC-Ni-Fe

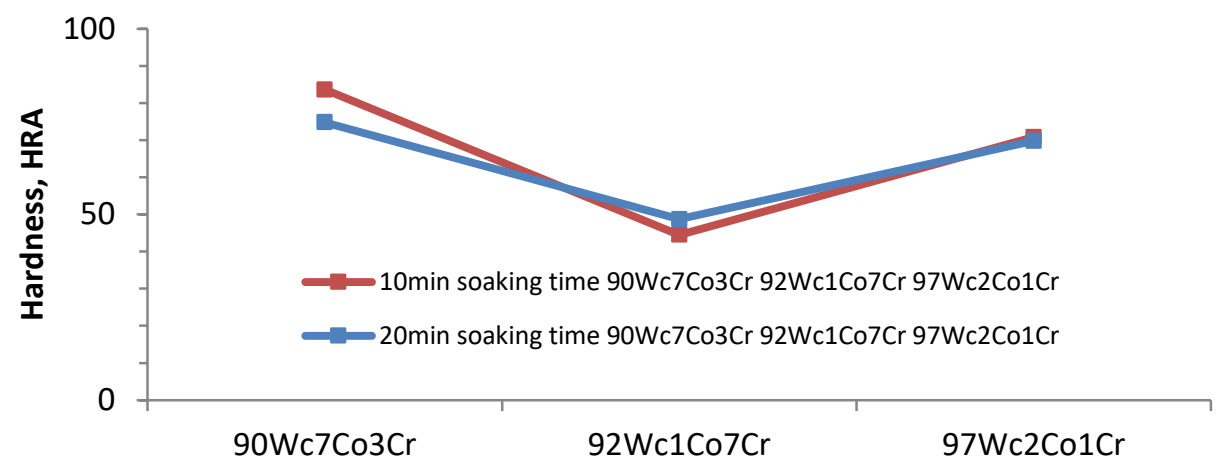

Figure 9. Hardness for 10min and 20 min soaking time for WC-Ni-Cr.

\section{Microstructural Analysis}

Comparison between NiFe and NiCr binders: All of the samples were compared between each binder that has the highest hardness result. The microstructure of the samples was taken from the surface of the sample. The binder, $\mathrm{NiFe}$ was compared to $\mathrm{NiCr}$ and the result showed that $\mathrm{NiFe}$ had better result on average for all of the hardness results. However, the compared between $92 \mathrm{WC} 1 \mathrm{Ni} 7 \mathrm{Fe}$ and $92 \mathrm{WC}-7 \mathrm{Ni}-1 \mathrm{Cr}$. It can be seen in Figure 10(b) that the grains had smaller pores than those in Figure 10(a). Moreover, the results show that Figure 10(b) had better densification and was harder than Figure 10(a). This is because Figure 10(b) had higher $\mathrm{Ni}$ and $\mathrm{Ni}$ is known as a binder that improves tungsten densification. Besides that, the melting temperature may be a factor for grains behavior. It is known that nickel has a melting temperature of $1453^{\circ} \mathrm{C}$, while $\mathrm{Fe}$ has higher melting temperature, which is $1536^{\circ} \mathrm{C}$. Due to this reason, nickel may have melted during the sintering process. When this happens, nickel arrives at the liquid phase and will be pulled by capillary forces into the narrow gaps between the particles of the solid component, creating the largest possible contact area between liquid and solid phases. Then, alloying takes place and, if the initial proportion of the liquid phase is smaller than its solubility in the solid phase, the liquid phase eventually disappears and leaves behind large pores [25]. A higher Ni volume fraction decreases the connectivity and moving resistance of WC particles and as a result enhances the rearrangement of WC particles and further substantially improves the densification. 


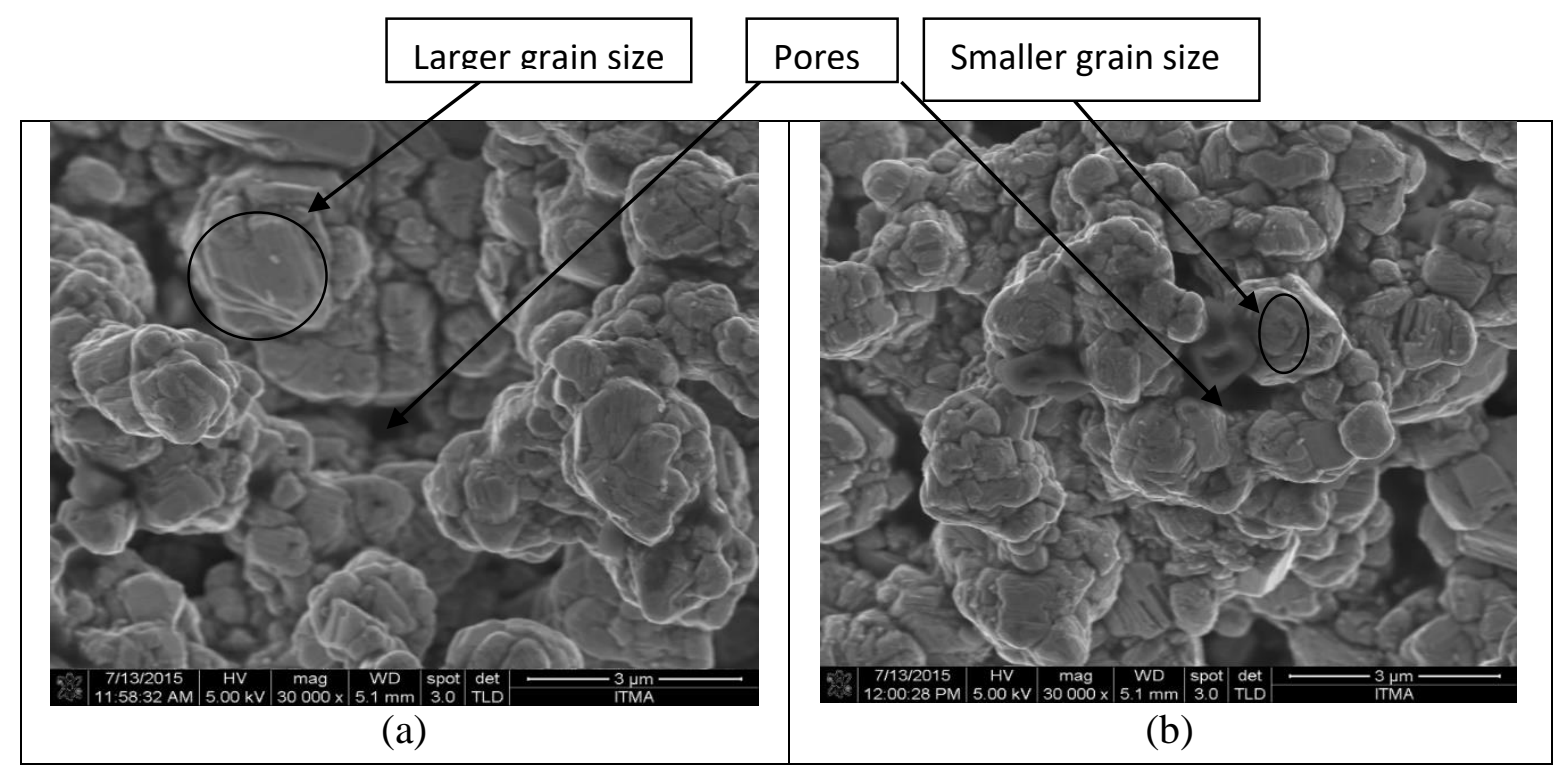

Figure 10. Microstructure of (a) $92 \mathrm{WC}-1 \mathrm{Ni}-7 \mathrm{Fe}$ and $92 \mathrm{WC}-7 \mathrm{Ni}-1 \mathrm{Cr}$

Comparison between $\mathrm{Co}-\mathrm{NiFe}$ and $\mathrm{Co}-\mathrm{Cr}$ binders: Based on the hardness result, there was not much difference on the microstructure because both samples had higher composition of cobalt and were slightly different in the hardness result, whereby Figure 11(a) had 83.7 and Figure 11(b) had 83.4 as the hardness result. Moreover, only few pores were found, which had the highest hardness for all 24 tested samples. This is because cobalt is known to have high strength with the addition of tungsten as compared to others that have been tried before. Moreover, Holleck [22] also found that $\mathrm{Cr}$ did not produce better result than other binders. While, by looking at the grain boundaries of both samples, it can be seen that Figure 11(b) had clearer grain boundaries compared to Figure 11(a). However, the pores and likely mostly on Figure 11(b). Moreover, as stated in MUREŞAN [16], the element of $\mathrm{Cr}$ forms interfaces with the elements of $\mathrm{W}, \mathrm{Ni}, \mathrm{Fe}$, and $\mathrm{O}$, and segregates along the alloy interface, which causes interface corrosion, and determines low mechanical properties of the mentioned alloys.

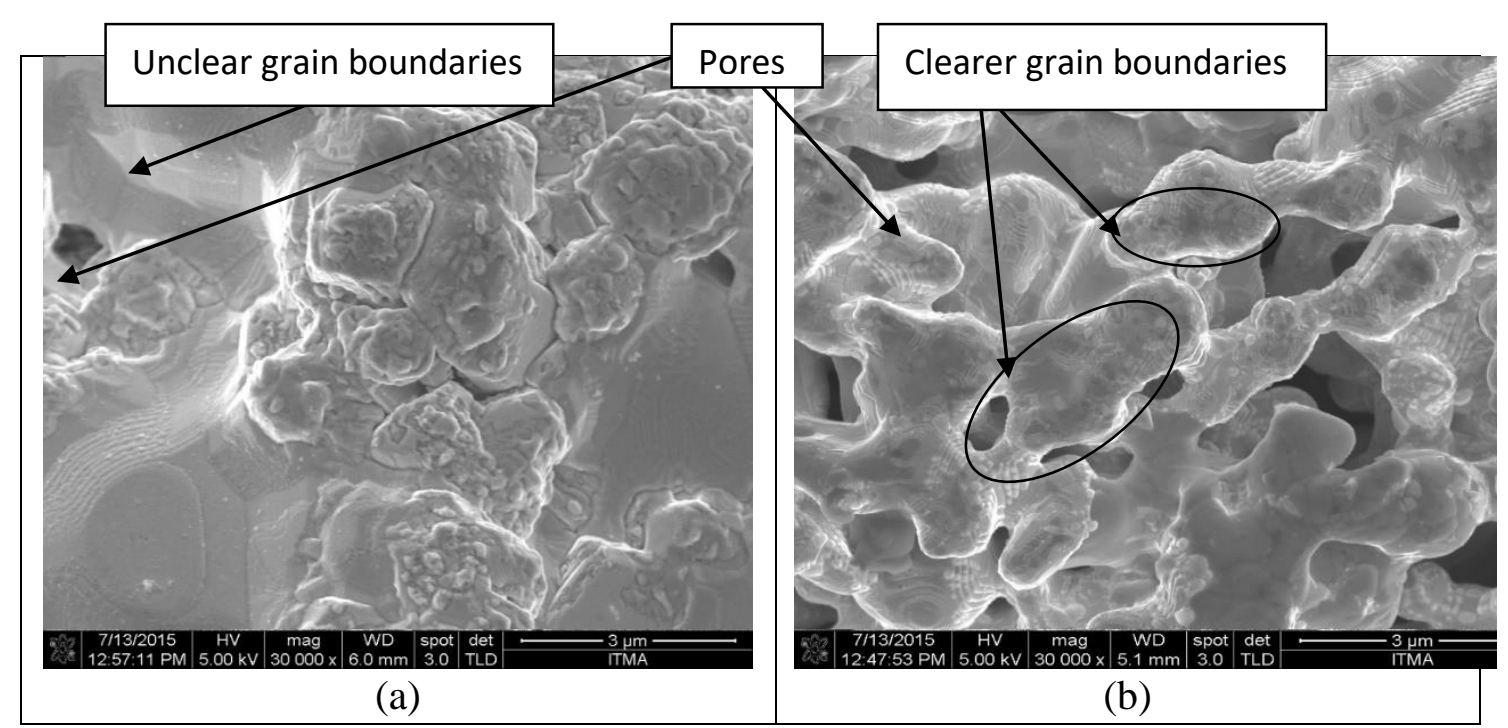

Figure 12: Microstructure of (a) $92 \mathrm{WC}-7 \mathrm{Co}-0.5 \mathrm{Ni}-0.5 \mathrm{Fe}$ and (b) $92 \mathrm{WC}-7 \mathrm{Ni}-1 \mathrm{Cr}$. 


\section{CONCLUSIONS}

Ten minutes soaking time showed better results compared to 20 minutes. This is because prolonged heating time $(20$ minutes $)$ at higher temperature $\left(1450^{\circ} \mathrm{C}\right)$ may have affected the properties of the powder. Thus this may lead to increased kinetic of the grain growth and coarser grain size as compared to shorter heating time (10 minutes). This then achieved the objectives of this research, where it can be seen that 10 minutes soaking time had an effect on density, hardness and the microstructures of each sample. Higher density and hardness results were obtained for 10 minutes soaking time as compared to 20 minutes, which resulted in low density and hardness. Between the binder of nickel and ferum $(\mathrm{Ni}, \mathrm{Fe})$ and nickel and chromium $(\mathrm{Ni}, \mathrm{Cr})$, the binder of $\mathrm{Ni}$ and $\mathrm{Fe}$ showed better results compared to the $\mathrm{Ni}$ and $\mathrm{Cr}$ binder. This has been stated above, whereby the addition of chromium did not increase the strength, but only improved the cutting tool performance. Moreover, it is known also that nickel addition improves the strength of tungsten. The binder $\mathrm{Co}, \mathrm{Ni}$ and $\mathrm{Fe}$ had enhanced results compared to the binder $\mathrm{Co}$ and Cr. Although it is said that small amounts of $\mathrm{Cr}$ in the Co binder in WC-Co is an improvement mechanism to improve cutting tool performance leading to strength, this could not be shown to improve the density of a sample by adding chromium. Therefore, from all of the results, it is proven that microwave is viable to be used to sinter ceramic parts, and the effects of sintering soaking time on the properties can be clearly been seen on the microstructure. Moreover, the effect of binders on the sintered components can also be seen. Thus by referring to the results of the effects of the binder, the sample can be used depending on the condition that needs to be used.

\section{ACKNOWLEDGEMENTS}

The authors would like to be obliged to University Putra Malaysia (UPM) for providing financial assistance under RUGS project number 05-02-12-1907RU and Universiti Perlis Malaysia (UNIMAP) for providing laboratory facilities.

\section{REFERENCES}

[1] Oghbaei M, Mirzaee O. Microwave versus conventional sintering: a review of fundamentals, advantages and applications. Journal of Alloys and Compounds. 2010;494:175-89.

[2] Rahman MM, Wardi MAS, Nor SSM. On the Effect of Feedstock Preparation on the Characteristics of Warm Formed Powder Compacts. International Journal of Automotive and Mechanical Engineering. 2013;8:1132-9.

[3] Agrawal D. Microwave sintering of ceramics, composites, metals, and transparent materials. Journal of Materials Education. 1997;19:49-58.

[4] Kitiwan M, Atong D. Application of Microwave Energy for Synthesis and Sintering of Al2O3-TiC Ceramics. Sigma. 2004;99:0.1 $\mu \mathrm{m}$.

[5] Rahman M, Wong YS, Zareena AR. Machinability of Titanium Alloys. JSME International Journal Series C. 2003;46:107-15.

[6] Agrawal DK. Microwave processing of ceramics. Current Opinion in Solid State and Materials Science. 1998;3:480-5.

[7] Kelvin Chew WJ, Niakan A, Nawawi NA, Bang LT, Ramesh S. Influence of powder morphology and sintering temperature on the properties of 
hydroxyapatite. International Journal of Automotive and Mechanical Engineering. 2015;12:3089-96.

[8] Sivakumar S, Ramesh S, Chin KL, Tan CY, Teng WD. Effect of Sintering Profiles on the Properties and Ageing Resistance of Y-TZP Ceramic. International Journal of Automotive and Mechanical Engineering. 2011;4:405-13.

[9] Sharif NS, Mohamed JJ, Derita HS, Ahmad ZA, Abdullah MZ, Mohamad H, et al. The effect of sintering conditions on the microstructure and electrical properties of $\mathrm{Pb}(\mathrm{Zr} 0.52 \mathrm{Ti0} .48) \mathrm{O} 3$ ceramic. Journal of Mechanical Engineering and Sciences. 2014;6:901-6.

[10] Ramesh S, Tan CY, Amiriyan M, Teng WD. Sintering effects on the densification of nanocrystalline hydroxyapatite. International Journal of Automotive and Mechanical Engineering. 2011;3:249-55.

[11] Aw PK, Tan ALK, Tan TP, Qiu J. Corrosion resistance of tungsten carbide based cermet coatings deposited by high velocity oxy-fuel spray process. Thin solid films. 2008;516:5710-5.

[12] Wentzel E, Allen C. The erosion-corrosion resistance of tungsten-carbide hard metals. International Journal of Refractory Metals and Hard Materials. 1997; 15:81-7.

[13] Thostenson E, Chou T-W. Microwave processing: fundamentals and applications. Composites Part A: Applied Science and Manufacturing. 1999;30:1055-71.

[14] Brożek M, Młynarczykowska A, Turno A. The relationship between deterministic and stochastic models of flotation. Archives of Mining Sciences. 2003;48:299314.

[15] Waldorf D, Liu S, Stender M, Norgan D. Alternative binder carbide tools for machining superalloys. ASME 2008 International Manufacturing Science and Engineering Conference collocated with the 3rd JSME/ASME International Conference on Materials and Processing: American Society of Mechanical Engineers; 2008. p. 417-25.

[16] Mureşan R. Study on the chrome influence on the mechanical properties and microstructure of the tungsten based alloys. Acta Technica Napocensis-Series: Applied Mathematics, Mechanics, And Engineering. 2016;59: 39-44.

[17] Zhou Y, Wang K, Liu R, Wang X, Liu C, Fang Q. High performance tungsten synthesized by microwave sintering method. International Journal of Refractory Metals and Hard Materials. 2012;34:13-7.

[18] Breval E, Cheng J, Agrawal D, Gigl P, Dennis M, Roy R, et al. Comparison between microwave and conventional sintering of WC/Co composites. Materials Science and Engineering: A. 2005;391:285-95.

[19] Moskowitz D. Iron-Nickel Bonded Tungsten Carbide. Proceedings of the 1st International Cemented Carbide Conference1971. p. 1-12.

[20] Bao R, Yi J, Zhang H, Peng Y. A research on WC-8Co preparation by microwave sintering. International Journal of Refractory Metals and Hard Materials. 2012;32:16-20.

[21] Willert-Porada M. A microstructural approach to the origin of" microwave effects" in sintering of ceramics and composites. Microwaves: Theory and Application in Materials Processing IV. 1997:153-63.

[22] Holleck H. Hard alloy comprising one or more hard phases and a binary or multicomponent binder metal alloy. Google Patents; 1984. 
[23] González R, Echeberría J, Sánchez J, Castro F. WC-(Fe, Ni, C) hardmetals with improved toughness through isothermal heat treatments. Journal of materials science. 1995;30:3435-9.

[24] Nelson DH, Schneider G. Applied manufacturing process planning: with emphasis on metal forming and machining: Prentice Hall; 2001.

[25] Hoganas A. Hoganas handbook for sintered components. Material and Powder Properties. 1997. 